Old Dominion University ODU Digital Commons

Psychology Faculty Publications

Psychology

2016

\title{
The Course and Interrelationship of Maternal and Paternal perinatal Depression
}

James F. Paulson

Old Dominion University, jpaulson@odu.edu

Sharnail D. Bazemore

Janice H. Goodman

Jenn A. Leiferman

Follow this and additional works at: https://digitalcommons.odu.edu/psychology_fac_pubs

Part of the Mental and Social Health Commons, and the Psychiatry and Psychology Commons

\section{Repository Citation}

Paulson, James F.; Bazemore, Sharnail D.; Goodman, Janice H.; and Leiferman, Jenn A., "The Course and Interrelationship of Maternal and Paternal perinatal Depression" (2016). Psychology Faculty Publications. 69.

https://digitalcommons.odu.edu/psychology_fac_pubs/69

\section{Original Publication Citation}

Paulson, J. F., Bazemore, S. D., Goodman, J. H., \& Leiferman, J. A. (2016). The course and interrelationship of maternal and paternal perinatal depression. Archives of Womens Mental Health, 19(4), 655-663. doi:10.1007/s00737-016-0598-4

This Article is brought to you for free and open access by the Psychology at ODU Digital Commons. It has been accepted for inclusion in Psychology Faculty Publications by an authorized administrator of ODU Digital Commons. For more information, please contact digitalcommons@odu.edu. 


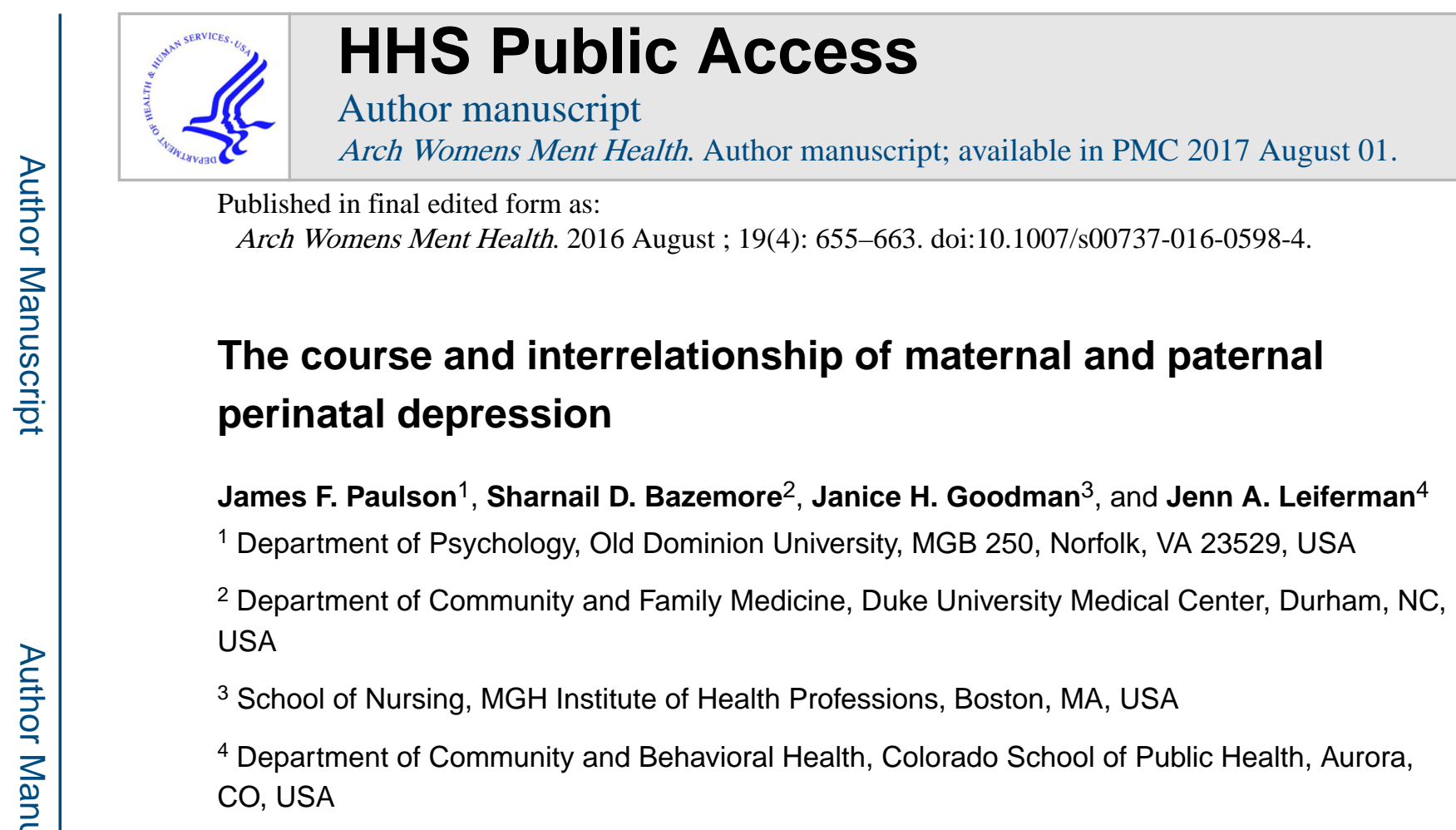

\section{Abstract}

The aims of the study were to describe course of depression in both mothers and fathers from the third trimester of pregnancy through 6 months postpartum and to examine the relationship between maternal and paternal depression. Hypotheses were as follows: (a) Depressive symptoms would be correlated between parents and (b) earlier depressive symptoms in one parent would predict later increases in depression in the other. Eighty cohabitating primiparous couples were recruited from prenatal OBGYN visits and community agencies and enrolled during pregnancy, between 28 -week gestation and delivery. Participants completed measures of depression on four occasions: baseline and 1, 3, and 6 months postpartum. Ninety-eight percent of the enrolled couples $(78 ; 156$ individuals) completed the study. For both mothers and fathers, symptom severity ratings and classification as a probable case were stable across time, with prenatal depression persisting through 6 months in $75 \%$ of mothers and $86 \%$ of fathers. Prenatal depression in fathers predicted worsening depressive symptom severity in mothers across the first six postpartum months but not vice versa. In both expecting/new mothers and fathers, depression demonstrates a stable pattern of occurrence and symptom severity between 28-month gestation and 6 months postpartum.

Although prenatal maternal depression is not predictive of symptom change in fathers, mothers with prenatally depressed partners showed significant worsening in overall symptom severity during the first six postpartum months.

\section{Keywords}

Depression; Family; Fathers; Perinatal depression

Maternal perinatal depression affects about $14 \%$ of women (Gavin et al. 2005). Its risk factors and child developmental consequences have been well documented (Beardslee et al.

James F. Paulson JPaulson@odu.edu.

Compliance with ethical standards

Conflict of interest The authors report no conflicts of interest. 
1998; Bennett et al. 2004; Gotlib et al. 1989). A complementary focus on depression in expecting and new fathers has only more recently taken shape. This emerging literature suggests that elevated depressive risk is also a problem for expecting and new fathers (Paulson and Bazemore 2010). Moreover, much like the literature on maternal depression, evidence regarding paternal depression points to increases in risks for the child, both in terms of relative impairments in parenting (Davis et al. 2011; Paulson et al. 2009) and longterm functioning in children (Ramchandani et al. 2008). Chronic maternal depression adds to the risk for poor outcomes in children, families, and long-term maternal mental health (Brennan et al. 2000). With the current knowledge base on paternal perinatal depression being at an early developmental stage, very little is understood regarding its course and chronicity.

A recent meta-analysis of paternal depression found that $100 \%$ of articles that reported on the correlation between maternal and paternal depression found elevated depressive symptomatology in one partner to be significantly associated with corresponding increases in the other's (Paulson and Bazemore 2010). Although these findings characterize one partner's depression as a significant risk for the other's, the direction of this effect across pregnancy and the postpartum year remains unexplored.

Longitudinal studies of maternal depression indicate that the rate of maternal depression is higher during pregnancy than during the postpartum period and that the majority of cases of postpartum depression are preceded by depression during pregnancy (Bowen et al. 2012; Heron et al. 2004; Lee and Chung 2007). It is unclear whether the intra-individual course of maternal depression tends to fluctuate or remain relatively stable throughout the perinatal period (Heron et al. 2004; Lee et al. 2007). Furthermore, the risk for depression remains elevated throughout the first postpartum year (Gaynes et al. 2005; Monti et al. 2008). Although maternal postpartum depression is often relatively short-lived, for many women, depression can become prolonged or chronic, especially if there is a history of major depression (Cooper and Murray 1995; Goodman 2004; Horowitz and Goodman 2004).

Fewer studies have examined paternal depression during this period, and longitudinal data on this topic are sparse (Paulson and Bazemore 2010). Two studies suggest that the prevalence of paternal depression decreases shortly after the birth of a baby and then gradually increases over the child's first year (Cox 2005; Matthey et al. 2000), whereas other studies show paternal depressive symptoms to be relatively stable throughout the perinatal period (Deater-Deckard et al. 1998; Raskin et al. 1990). Our review identified no studies that document the longitudinal interrelationship between maternal and paternal depression.

At present, our understanding of course and chronicity of maternal depression from pregnancy to postpartum is incomplete. Because parallel information on the presence and course of paternal chronicity is unavailable, it has not been established how one parent's depression may influence the other's. In this article, we aim to describe the course and interrelationship of depression in both mothers and fathers from the third trimester of pregnancy through 6 months postpartum. We focus on first-time parents in order to characterize course in the absence of family size, ages of other children, or other complicating factors. Our hypotheses were that (a) depressive severity at any time point 
would be correlated between parents and (b) more severe prenatal symptomatology in one parent would predict the same in the other in the first six postpartum months.

\section{Materials and methods}

We recruited 80 male-female pairs from local OBGYN practices, childbirth preparation courses, and electronic announcements posted in a variety of other community forums. All participants enrolled in the study during the mother's third trimester of pregnancy ( 28 weeks to term). Only participants expecting their first child together were included (all mothers were nulliparous, but some fathers had biological children living elsewhere). Participants with a history of major mental illness (bipolar disorder or a psychotic disorder), those who were expecting to leave the area during the study, and those unable to complete paper and pencil questionnaires in English were excluded. Of an initial pool of 120 interested couples, 83 were eligible and 80 ultimately enrolled in the study (96\% enrollment rate). All participants were followed at four study visits occurring at (1) pregnancy, between 28 -week gestation and birth; (2) 1 month postpartum; (3) 3 months postpartum; and (4) 6 months postpartum. Visits 1, 3, and 4 were in-person and conducted in participants' homes or our laboratory (selected based on participants' preference) and visit 2 was conducted via telephone for participants' convenience. During each visit, participants completed several questionnaires, interviews, and family activities, the relevant instruments being described below. Informed consent and all other study procedures were approved and overseen by the Institutional Review Boards at Eastern Virginia Medical School and Old Dominion University.

The Center for Epidemiologic Studies Depression Scale (CES-D) is a 20-item, four-point Likert-type scale, self-report questionnaire intended to measure depressive symptomatology in non-clinical populations. Respondents are asked to rate how often during the past week they experienced the 20 symptoms listed. The CES-D is a reliable $(a=.85)$ and valid tool that has been used extensively in past research (Radloff 1977). Further, the CES-D permits measurement convergence between general and population-specific depression measures. In this study, we report on both depressive severity, as measured by the total CES-D score, and probable depression caseness, defined by the common threshold of scores $\geq 16$.

The Edinburgh Postnatal Depression Scale (EPDS) is a self-report ten-item tool that has been used extensively in the past to assist in the identification of women who may be suffering from prepartum or postpartum depression (Cox et al. 1987), and in new and expecting fathers (Madsen and Juhl 2007; Perren et al. 2005; Ramchandani et al. 2005). Item analysis of the EPDS in fathers has found lower rates of endorsement on items but suggests that it corresponds well to diagnostic interview-based assessment when slightly lower cutoffs are used (Matthey et al. 2001). The EPDS places greater emphasis on cognitive and affective symptoms of depression while de-emphasizing somatic symptoms-beneficial in pregnancy and postpartum when fatigue and other somatic symptoms are common and unreliable indicators of depression. Across validation studies of the EPDS, reliability is consistently high $(\alpha>.80)$. In women, major depression cutoffs have yielded a specificity of $92.5 \%$ and a positive predictive value of $56.8 \%$ (Carothers and Murray 1990). One study using the EPDS in fathers found that a cutoff of $\geq 10$ yields a specificity of $93.8 \%$ and a 
positive predictive value of $29.4 \%$ (Matthey et al. 2001). In this study, we report on both depressive severity, as measured by the total EPDS score, as well as using case identification cutoffs in the EPDS, defined in mothers by scores $\geq 12$ and in fathers by scores of $\geq 10$.

Because the EPDS includes an item that assesses self-harm ideation, we put a screening and referral protocol in place for all participants, which was utilized for two mothers at the 6month visit. Because data collection had concluded for these families at the time they were screened, no adjustments or additional analyses were conducted for their cases.

Two scales (rather than one) were selected to measure depression because the EPDS, although beneficial because of its exclusion of physical symptoms of depression, remains a novel instrument for assessing depression among expecting and new fathers. As such, the inclusion of the CES-D permits measurement convergence between general and populationspecific depression measures.

To ensure a range of depressive symptom presentations, participants were recruited from depression strata (determined by probable caseness on either the EPDS or CES-D): (a) neither screened positive, (b) father only screened positive, (c) mother only screened positive, and (d) both screened positive. Although the study obtained greater number of participants in group $a(n=28)$ and smaller numbers for groups $b(n=18), c(\mathrm{n}=16)$, and $d$ $(n=18)$, this scheme, while producing inflated point estimates of depression at baseline, still allows us to examine longitudinal course of depression. Moreover, the over-representation of depressed individuals is advantageous in terms of understanding how these symptoms and related experiences change across late pregnancy and in early parenthood.

\section{Results}

\section{Recruitment and retention}

Of the 80 mother-father pairs who enrolled in the study, two families were lost to follow-up by 6 months postpartum (97.5\% retention). Our sample self-reported as primarily White (similar to the region) with a modal education level of Bsome college ${ }^{\wedge}$ or an Associate's degree. Most ( $82 \%$ fathers, $62 \%$ mothers) were employed full time and about $12 \%$ were full-time students. Median household income was \$50,001-\$75,000. Most couples (87\%) were married and $72 \%$ of pregnancies were planned. See Table 1.

\section{Rates of depression over time in the full sample}

The CES-D and EPDS were used together to classify depressive caseness, which was coded as present if a participant scored above the threshold on either measure at a given time point. As expected, due to the oversampling of couples who reported elevated depression at screening, higher rates of depression ( $20.5 \%$ of fathers and $32.1 \%$ of mothers) were observed in both mothers and fathers in the prenatal period. At 1 month postpartum, both parents demonstrated a decrease in depression when compared to prenatal rates (fathers, $\Delta=$ $-24.3 \%$; mothers, $\Delta=-15.4 \%$ ). Maternal rates of depression continued to decline at 3 and 6 months, whereas paternal rates increased by $7.6 \%$ by 3 months and remained stable. See Table 2. 


\section{Depressive symptomatology over time in the full sample}

Average depressive symptom severity also declined in a roughly linear fashion, with patterns of symptom severity decline being similar for mothers and fathers. See Fig. 1.

\section{Persistence and remission of depression}

Among the 24 mothers who were defined as depression cases in the third trimester visit, 18 ( $75 \%$ ) continued to meet case definition criteria by 6 months postpartum. Similarly, most cases identified at 1 month postpartum and 3 months postpartum continued to meet criteria by 6 months ( 79 and $86 \%$, respectively). Of the 24 mothers who were depressed at the thirrd trimester visit, 17 (71\%) were classified as depressed at all three subsequent visits, whereas none of the mothers who were not depressed prenatally showed this pattern of postpartum chronicity.

Among the 14 fathers who were defined as depression cases in the third trimester visit, 12 $(86 \%)$ met case definition criteria at 6 months postpartum. Similarly, most cases identified at 1 month postpartum and 3 months postpartum continued to meet criteria by 6 months ( 85 and $86 \%$, respectively). Similar to mothers, 11 of the 14 (79\%) fathers who were depressed at the prenatal visit were classified as depressed at all subsequent visits. See Table 3.

\section{Stability of depressive symptomatology}

Depressive symptom severity was relatively stable within both mothers and fathers across time, with stability coefficients (measured by Pearson product-moment correlation) that ranged from .70 to .43 in mothers and .75 to .53 in fathers. As expected, correlations between measures of depression taken at more distant time points were significant but somewhat smaller in value. See Table 4.

\section{Associations between partners' depressive symptom severity}

Repeated measures analysis of variance was used to examine how each parent's prenatal depression predicted the other's level and course of postpartum depressive symptom severity. Because depressive symptoms and depression status were observed to be relatively stable within each individual, baseline depressive symptom severity was statistically controlled in order to assess the incremental influence of the other partner's depression. These analyses also controlled for maternal and paternal income, which was highly correlated with education, race, and employment status (omitted from the model because of colinearity).

Father's prenatal depressive status was associated with a significantly altered course of maternal postpartum depressive symptoms when measured by both the CES-D $(\mathrm{F}(2,70)=$ $3.57, p=.033$, partial $\left.\eta^{2}=.093\right)$ and the $\operatorname{EPDS}\left(\mathrm{F}(2,68)=3.90, p=.025\right.$, partial $\left.\eta^{2}=.103\right)$. With each of these metrics, maternal depressive severity demonstrated a worsening postpartum pattern when fathers were depressed prenatally, whereas maternal depression showed improvement when fathers were not depressed prenatally. Binary logistic regression showed that mothers with prenatally depressed partners were 4.2 times more likely to have worsened depressive symptoms at 6 months than were those with prenatally non-depressed partners (odds ratio $(\mathrm{OR})=4.16,95 \%$ confidence interval $(95 \% \mathrm{CI})=(1.06,16.32), p=$. 041). 
In contrast, mother's prenatal depression status did not predict the course or level of postpartum paternal depression, as measured by the CES-D $(\mathrm{CES}-\mathrm{D}(\mathrm{F}(2,69)=0.14, p=$. 873 , partial $\left.\eta^{2}=.004\right)$ or the EPDS $\left(\mathrm{F}(2,67)=0.05, p=.951\right.$, partial $\left.\eta^{2}=.002\right)$. Logistic regression also found no association between prenatal maternal depression and overall change of symptoms in fathers $(\mathrm{OR}=1.25,95 \% \mathrm{CI}=(0.48,3.28), p=.650)$. See Fig. 2 .

\section{Discussion}

Perinatal depression in mothers has long been understood to be prevalent and deleterious to the developing child and the young family (Beardslee et al. 1998). Recent evidence suggests that paternal depression poses similar risks for children (Ramchandani et al. 2008) and may be linked to maternal depression (Paulson and Bazemore 2010). This study uses a cohort of mother-father pairs, followed from pregnancy to six months postpartum. It is the first study of its kind to use parallel measurement of depression in both parents at multiple time points, spaced closely enough to roughly characterize both parents' course of symptoms during pregnancy and early infancy. In addition to providing information on depressive course, the parallel measurement in both parents was used to examine the interaction between paternal and maternal depression across this time period, information that may be important for screening, prevention, and treatment.

Due to our oversampling strategy, baseline depression rates were high in both mothers $(32.1 \%)$ and fathers $(20.5 \%)$ when compared to national estimates (mothers, $14 \%$; fathers, $10 \%$ ) (Gavin et al. 2005; Paulson and Bazemore 2010). Our analysis indicates that, although depressive symptom severity declined somewhat from the prenatal measurement to 6 months postpartum, both symptom severity and rates of depression were quite stable. Among mothers who were depressed in the third trimester, $75 \%$ continued to be depressed by 6 months postpartum with only $14 \%$ of cases that were initially non-depressed meeting case definition criteria at any of the three postpartum time points. Fathers showed a similar stability, with $86 \%$ of prenatally depressed cases continuing to meet case definition criteria at all three postpartum time points. These findings are consistent with prior literature that suggests symptom stability from late pregnancy through the first postpartum year (Moss et al. 2009) among women. This is the first study to identify a similar pattern among fathers during this same time period.

Prenatal depression in fathers was a significant predictor of change in maternal depression across the postpartum period; mothers with prenatally depressed partners showed worsening depressive symptoms whereas mothers with prenatally non-depressed partners showed an improving symptom course. In terms of the predictive value of prenatal paternal depression, it is noteworthy that mothers whose partners were depressed were more than four times more likely to have worsened symptoms by 6 months postpartum. Prior studies have suggested a role of cumulative psychosocial stressors, including financial distress and poor social support, in predicting maintained or worsening depressive symptoms postpartum (Klier et al. 2008). Our current findings suggest that early paternal depression incrementally increases the risk for continued or worsened maternal depressive symptoms through 6 months postpartum. 
Although a number of authors have suggested that maternal depression is the likely causal factor in its observed correlation with paternal depression (Dudley et al. 2001; Schumacher et al. 2008), our findings suggest the opposite. We found that earlier maternal depression did not predict changes in paternal depressive symptoms over time. Although our data do not explain why maternal depression was affected by earlier paternal depression but not vice versa, most of our study mothers remained at home with their newborns for longer periods of time than did the fathers, who most often returned to work soon after the birth. Fathers' easier access to a greater breadth of social contacts may have buffered them from these effects.

In terms of strengths, the current study utilized a prospective design that included parallel measurement in mothers and fathers. Because of the relatively close timing of study visits, we were able to characterize trends in maternal and paternal depression over the short but often unstable time during which expecting parents transition and adjust to new parenthood. This timing is also advantageous in terms of intervention and prevention, as expecting and new parents attend frequent medical visits and may be uniquely attuned to efforts that originate in these settings. Important in this context was our notably low attrition rate (2\%), which is often a source of bias in similar studies. Furthermore, the measures used to assess depression are both well accepted in terms of reliability and validity and widely used in medical practices, underscoring the generalizability of study findings.

Some limitations of our study should be acknowledged. Our design included an oversampling of couples in which at least one partner was experiencing elevated prenatal depression. For this reason, reported depression rates are overestimates of the underlying population from which participants were selected. Furthermore, participants were not randomly sampled from the population and the final sample was disproportionately white, married, and more educated. This may limit the generalizability of our findings. Importantly, the classification of depression into probable cases versus non-cases was done via symptom questionnaire rather than clinical diagnosis. Although this method of case identification is closely parallel (Vredenburg et al. 1993), it remains a proxy for clinical diagnosis.

Our findings have several implications that should be considered for practical or clinical application. Principally, paternal depressive symptoms are consistently correlated with maternal symptoms and the presence of significant paternal symptoms during late pregnancy is a clear predictor of a poorer maternal course. In addition to conducting screenings, which the American College of Obstetricians and Gynecologists suggests may greatly benefit mothers and their families (American College of Obstetricians and Gynecologists 2010), healthcare providers working with pregnant women and new mothers should also make efforts to include fathers in health assessments. This may be important for both for the improvement of overall early family health and for the welfare of the mother, who may struggle with increased depressive symptoms themselves when their partners are also depressed. Although the literature on timing of screening for perinatal depression in fathers is poorly developed, some evidence suggests that depression timing may be parallel to maternal depression. Future studies examining maternal or paternal depression should include measures of both partners, as the present findings affirm a growing body of evidence showing the correlation between partners' depressive symptoms (Paulson and Bazemore 
2010). At present, despite the documentation of various ways in which maternal and paternal depressive symptoms are associated with one another, relatively little work has been done to explore the mechanisms through which these are associated. Identifying family interactions or examining models of cumulative family stress will be a next important step in this research that may identify points of leverage around which interventions might be designed.

\section{Acknowledgments}

Portions of this work were funded by a grant from the Eunice Kennedy Shriver National Institute of Child Health and Human Development (1R21HD060942). 3

\section{References}

American College of Obstetricians and Gynecologists. Screening for depression during and after pregnancy. ACOG; Albany: 2010.

Beardslee WR, Versage EM, Gladstone TR. Children of affectively ill parents: a review of the past 10 years. J Am Acad Child Adolesc Psychiatry. 1998; 37:1134-1141. [PubMed: 9808924]

Bennett HA, Einarson A, Taddio A, Koren G, Einarson TR. Prevalence of depression during pregnancy: systematic review. Obstet Gynecol. 2004; 103:698-709. [PubMed: 15051562]

Bowen A, Bowen R, Butt P, Rahman K, Muhajarine N. Patterns of depression and treatment in pregnant and postpartum women. Can J Psychiatry. 2012; 57:161-167. [PubMed: 22398002]

Brennan P, Hammen C, Andersen M, Bor W. Chronicity, severity, and timing of maternal depressive symptoms: relationship with child outcomes at age 5. Dev Psychol. 2000; 36:759-766. [PubMed: 11081699]

Carothers AD, Murray L. Estimating psychiatric morbidity by logistic regression: application to postnatal depression in a community sample. Psychol Med. 1990; 20:695-702. [PubMed: 2236379]

Cooper PJ, Murray L. Course and recurrence of postnatal depression. Evidence for the specificity of the diagnostic concept. Br J Psychiatry. 1995; 166:191-195. [PubMed: 7728362]

Cox J. Postnatal depression in fathers. Lancet. 2005; 366:982. [PubMed: 16168775]

Cox J, Holden J, Sogovsky R. Detection of postnatal depression-development of the 10-item Edinburgh postnatal depression scale. Br J Psychiatry. 1987; 150:782-786. [PubMed: 3651732]

Davis RN, Davis MM, Freed GL, Clark SJ. Fathers' depression related to positive and negative parenting behaviors with 1-year-old children. Pediatrics. 2011; 127:612-618. doi:10.1542/peds. 2010-1779. [PubMed: 21402627]

Deater-Deckard K, Pickering K, Dunn JF, Golding J. Family structure and depressive symptoms in men preceding and following the birth of a child. The Avon longitudinal study of pregnancy and childhood study team. Am J Psychiatry. 1998; 155:818-823. [PubMed: 9619156]

Dudley M, Roy K, Kelk N, Bernard D. Psychological correlates of depression in fathers and mothers in the first postnatal year. J Reprod Infant Psychol. 2001; 19:187-202.

Gavin NI, Gaynes BN, Lohr KN, Meltzer-Brody S, Gartlehner G, Swinson T. Perinatal depression: a systematic review of prevalence and incidence. Obstet Gynecol. 2005; 106:1071-1083. doi: 10.1097/01.AOG.0000183597.31630.db. [PubMed: 16260528]

Gaynes BN, Gavin N, Meltzer-Brody S, et al. Perinatal depression: prevalence, screening, accuracy, and screening outcomes. Evid Reprod Technol Assess (Summ). 2005; 119:1-8.

Goodman JH. Paternal postpartum depression, its relationship to maternal postpartum depression, and implications for family health. J Adv Nurs. 2004; 45:26-35. [PubMed: 14675298]

Gotlib I, Whiffen V, Mount J, Milne K, Cordy N. Prevalence rates and demographic characteristics associated with depression in pregnancy and postpartum. J Consult Clin Psychol. 1989; 57:269274. [PubMed: 2785127]

Heron J, O'Connor TG, Evans J, Golding J, Glover V. The course of anxiety and depression through pregnancy and the postpartum in a community sample. J Affect Disord. 2004; 80:65-73. doi: 10.1016/j.jad.2003.08.004. [PubMed: 15094259] 
Horowitz JA, Goodman J. A longitudinal study of maternal post-partum depression symptoms. Res Theory Nurs Pract. 2004; 18:149-163. [PubMed: 15553344]

Klier CM, Rosenblum KL, Zeller M, Steinhardt K, Bergemann N, Muzik M. A multirisk approach to predicting chronicity of postpartum depression symptoms. Depress Anxiety. 2008; 25:718-724. doi:10. 1002/da.20419. [PubMed: 18729148]

Lee DT, Chung TK. Postnatal depression: an update. Best Pract Res Clin Obstet Gynaecol. 2007; 21:183-191. doi:10.1016/j.bpobgyn.2006.10.003. [PubMed: 17157072]

Lee AM, Lam SK, Sze Mun Lau SM, Chong CS, Chui HW, Fong DY. Prevalence, course, and risk factors for antenatal anxiety and depression. Obstet Gynecol. 2007; 110:1102-1112. doi: 10.1097/01.AOG.0000287065.59491.70. [PubMed: 17978126]

Madsen SA, Juhl T. Paternal depression in the postnatal period assessed with traditional and male depression scales. J Men's Health Gender. 2007; 4:26-31.

Matthey S, Barnett B, Ungerer J, Waters B. Paternal and maternal depressed mood during the transition to parenthood. J Affect Disord. 2000; 60:75-85. [PubMed: 10967366]

Matthey S, Barnett B, Kavanagh DJ, Howie P. Validation of the Edinburgh Postnatal Depression Scale for men, and comparison of item endorsement with their partners. J Affect Disord. 2001; 64:175184. [PubMed: 11313084]

Monti F, Agostini F, Marano G, Lupi F. The course of maternal depressive symptomatology during the first 18 months postpartum in an Italian sample. Arch Womens Ment Health. 2008; 11:231-238. doi: 10.1007/s00737-008-0017-6. [PubMed: 18493711]

Moss KM, Skouteris H, Wertheim EH, Paxton SJ, Milgrom J. Depressive and anxiety symptoms through late pregnancy and the first year post birth: an examination of prospective relationships. Arch Womens Ment Health. 2009; 12:345-349. doi:10.1007/s00737-009-0086-1. [PubMed: 19565328]

Paulson JF, Bazemore SD. Prenatal and postpartum depression in fathers and its association with maternal depression: a meta-analysis. JAMA. 2010; 303:1961-1969. doi:10.1001/jama.2010.605. [PubMed: 20483973]

Paulson JF, Keefe HA, Leiferman JA. Early parental depression and child language development. J Child Psychol Psychiatry. 2009; 50:254-262. doi:10.1111/j.1469-7610.2008.01973.x. [PubMed: 19175819]

Perren S, von Wyl A, Burgin D, Simoni H, von Klitzing K. Depressive symptoms and psychosocial stress across the transition to parenthood: associations with parental psychopathology and child difficulty. J Psychosom Obstet Gynaecol. 2005; 26:173-183. [PubMed: 16295515]

Radloff LS. The CES-D scale: a self-report depression scale for research in the general population. J Appl Psychol Measure. 1977; 1:385-401.

Ramchandani P, Stein A, Evans J, O'Connor TG. Paternal depression in the postnatal period and child development: a prospective population study. Lancet. 2005; 365:2201-2205. [PubMed: 15978928]

Ramchandani PG, Stein A, O'Connor TG, Heron J, Murray L, Evans J. Depression in men in the postnatal period and later child psychopathology: a population cohort study. J Am Acad Child Adolesc Psychiatry. 2008; 47:390-398. [PubMed: 18388761]

Raskin VD, Richman JA, Gaines C. Patterns of depressive symptoms in expectant and new parents. Am J Psychiatry. 1990; 147:658-660. [PubMed: 2327497]

Schumacher M, Zubaran C, White G, White G. Bringing birth-related paternal depression to the fore women and birth. J Aust College Midwives. 2008; 21:65-70.

Vredenburg K, Flett GL, Krames L. Analog versus clinical depression - a critical reappraisal. Psychol Bull. 1993; 113:327-344. doi:10.1037/ 0033-2909.113.2.327. [PubMed: 8451338] 

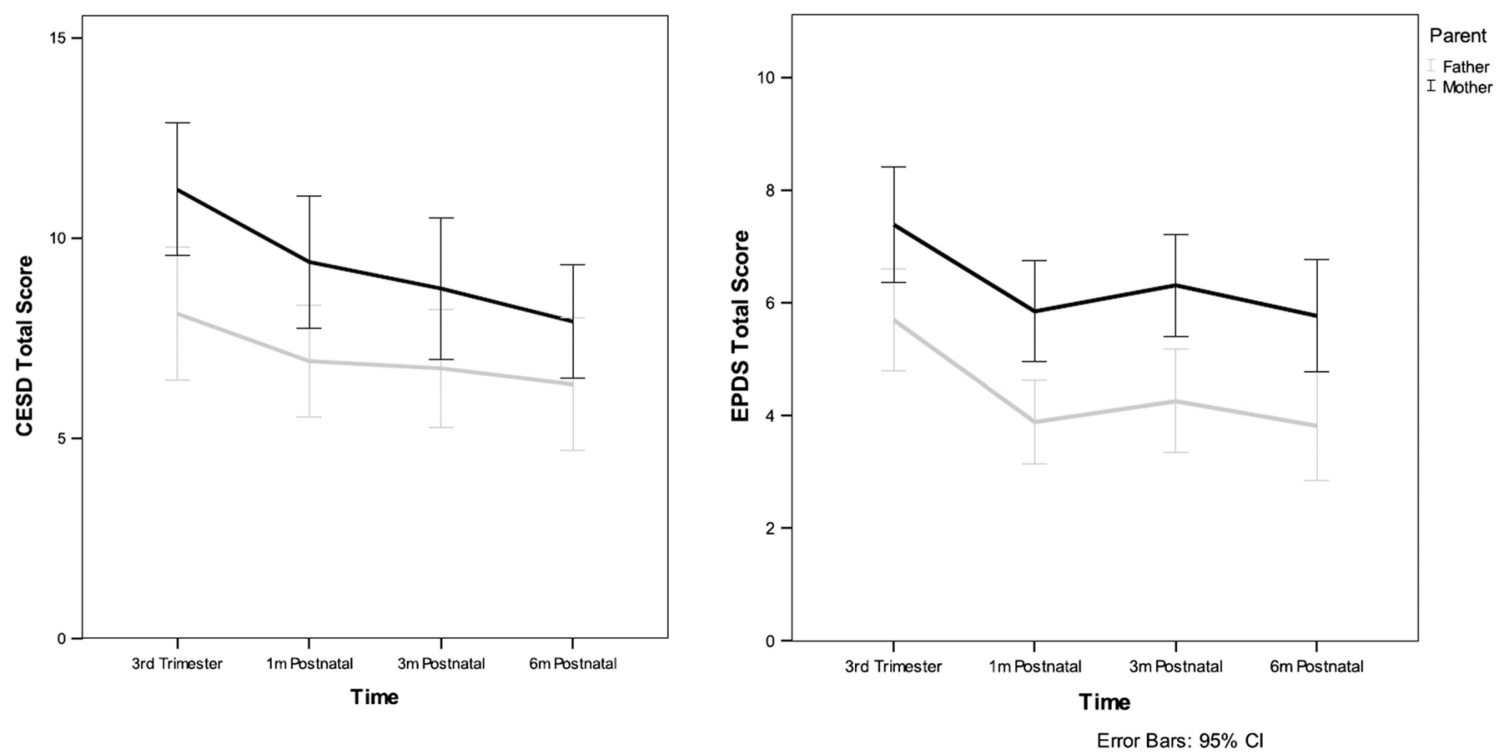

Fig. 1.

Depressive symptom severity from third trimester to 6 months postpartum 

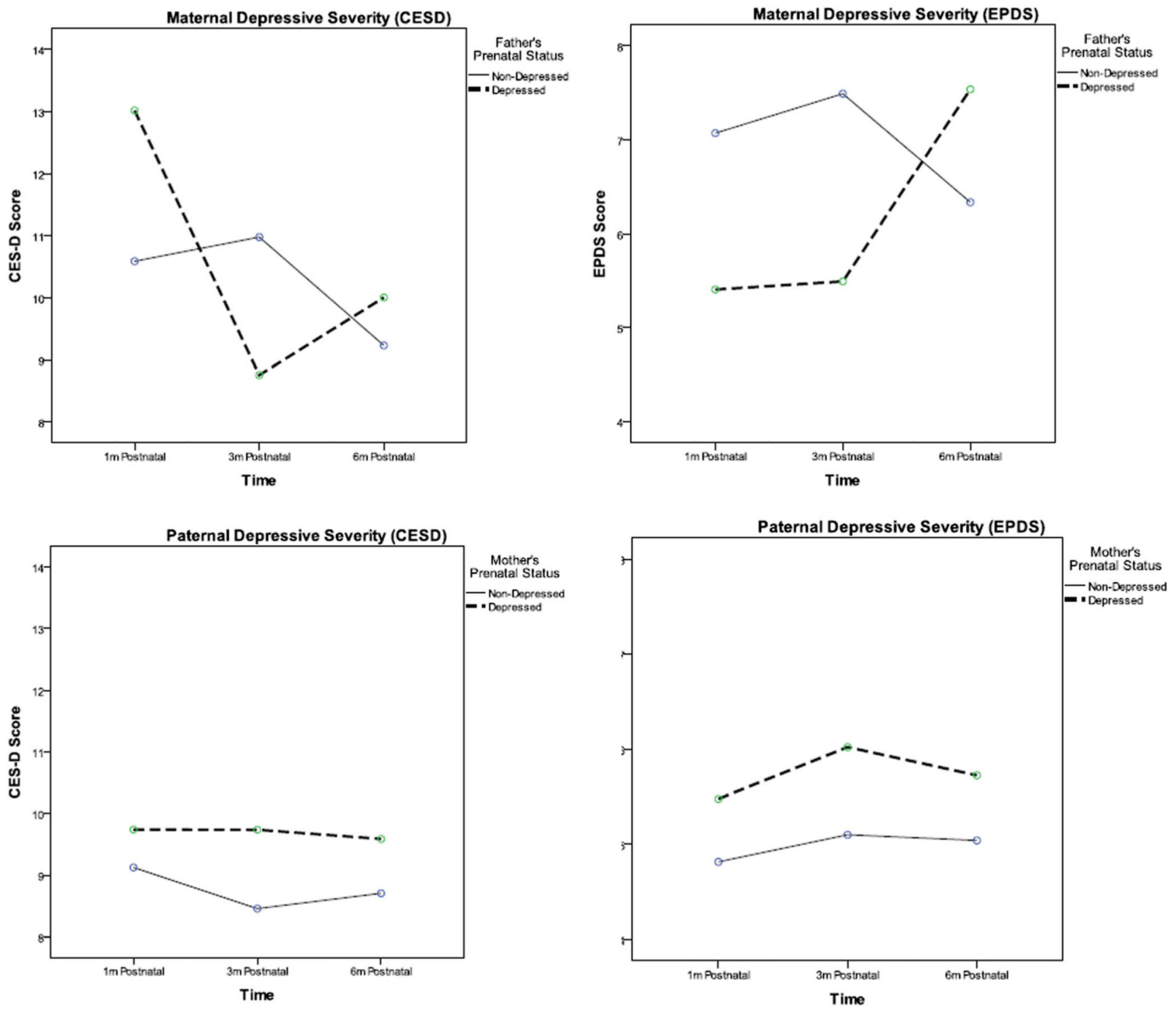

Fig. 2.

Postpartum course of depressive symptom severity change as a function of partner's prenatal depression status 
Table 1

Sample demographics

\begin{tabular}{|c|c|c|c|c|c|c|}
\hline \multirow[b]{2}{*}{ Mean age (SD) } & \multicolumn{2}{|c|}{ Mothers } & \multicolumn{2}{|c|}{ Fathers } & \multicolumn{2}{|c|}{ Total sample } \\
\hline & 28.5 & (6.4) & 30.6 & $(6.8)$ & 29.6 & (6.6) \\
\hline & $n$ & $(\%)$ & $n$ & $(\%)$ & $n$ & $(\%)$ \\
\hline \multicolumn{7}{|l|}{ Race/ethnicity } \\
\hline White & 56 & $(71.8)$ & 58 & (74.4) & 114 & (73.1) \\
\hline Black/African American & 8 & $(10.3)$ & 7 & $(9.0)$ & 15 & (9.6) \\
\hline Hispanic or Latino & 7 & $(9.0)$ & 6 & (7.7) & 13 & $(8.3)$ \\
\hline Asian & 2 & (2.6) & 2 & (2.6) & 4 & (2.6) \\
\hline Other/multiracial & 5 & (6.4) & 5 & (6.4) & 10 & (6.4) \\
\hline \multicolumn{7}{|l|}{ Education } \\
\hline High school diploma/GED or less & 5 & $(5.1)$ & 10 & (12.8) & 15 & (9.6) \\
\hline Some college, trade school, or associate's degree & 27 & $(34.6)$ & 27 & (34.6) & 54 & (34.6) \\
\hline Bachelor's degree & 21 & $(26.9)$ & 20 & (25.6) & 41 & $(26.3)$ \\
\hline Master's degree & 16 & $(20.5)$ & 18 & $(23.1)$ & 34 & (21.8) \\
\hline Doctorate degree & 9 & $(11.5)$ & 2 & $(2.6)$ & 11 & $(7.1)$ \\
\hline \multicolumn{7}{|l|}{ Employment status } \\
\hline Full-time & 48 & $(61.5)$ & 64 & $(82.1)$ & 112 & (71.8) \\
\hline Part-time & 9 & $(11.5)$ & 5 & $(6.4)$ & 14 & $(9.0)$ \\
\hline Unemployed & 12 & $(15.4)$ & 5 & (6.4) & 17 & (10.9) \\
\hline \multicolumn{7}{|l|}{ Military status } \\
\hline Active duty & 1 & (1.3) & 7 & $(9.0)$ & 8 & (5.1) \\
\hline Reserves & 0 & $(0)$ & 3 & (3.8) & 3 & (1.9) \\
\hline \multicolumn{7}{|l|}{ Student status } \\
\hline Full-time & 11 & $(14.1)$ & 7 & $(9.0)$ & 18 & (11.5) \\
\hline Part-time & 4 & $(5.1)$ & 4 & $(5.1)$ & 8 & $(5.1)$ \\
\hline \multicolumn{7}{|l|}{ Annual household income } \\
\hline$\$ 10,000-\$ 20,000$ & - & - & - & - & 5 & (6.4) \\
\hline$\$ 20,001-\$ 30,000$ & - & - & - & - & 6 & (7.7) \\
\hline$\$ 30,001-\$ 40,000$ & - & - & - & - & 12 & (15.4) \\
\hline$\$ 40,001-\$ 50,000$ & - & - & - & - & 4 & $(5.1)$ \\
\hline$\$ 50,001-\$ 75,000$ & - & - & - & - & 14 & (17.9) \\
\hline$>\$ 75,000$ & - & - & - & - & 37 & (47.4) \\
\hline Marital status & - & - & - & - & & \\
\hline Married & - & - & - & - & 68 & $(87.2)$ \\
\hline Unmarried & - & - & - & - & 10 & (12.8) \\
\hline Pregnancy intentions & - & - & - & - & & \\
\hline Planned & - & - & - & - & 56 & (71.8) \\
\hline Unplanned & - & - & - & - & 22 & $(28.2)$ \\
\hline Pregnancy health status & - & - & - & - & & \\
\hline High-risk & - & - & - & - & 15 & (19.2) \\
\hline
\end{tabular}




\begin{tabular}{lllllll}
\hline & Mothers & Fathers & & \multicolumn{2}{c}{ Total sample } \\
\hline Not high-risk & - & - & - & - & 57 & $(73.1)$ \\
Unsure & - & - & - & - & 6 & $(7.7)$ \\
Sex of infant & - & - & - & - & & \\
Male & - & - & - & - & 36 & $(46.2)$ \\
Female & - & - & - & - & 42 & $(53.8)$ \\
\hline
\end{tabular}

$N=78$ 
Table 2

Rates of depression across the perinatal period

\begin{tabular}{lllrl}
\hline Parent & Time & Mean rate $(\%)$ & \multicolumn{2}{c}{ 95 \% confidence interval } \\
\cline { 3 - 5 } Father & Third trimester & 34.6 & Lower $(\%)$ & Upper (\%) \\
\cline { 2 - 5 } & 1 month postpartum & 10.3 & 25.5 & 43.7 \\
& 3 months postpartum & 17.9 & 1.2 & 19.4 \\
& 6 months postpartum & 17.9 & 8.9 & 27.0 \\
\multirow{2}{*}{ Mother } & Third trimester & 38.5 & 8.9 & 27.0 \\
& 1 month postpartum & 23.1 & 29.4 & 47.6 \\
& 3 months postpartum & 19.2 & 14.0 & 32.2 \\
& 6 months postpartum & 16.7 & 10.1 & 28.3 \\
\hline
\end{tabular}




\section{Table 3}

Persistence or remission of depression

\begin{tabular}{llllll}
\hline & $\mathbf{N}(\boldsymbol{\%})$ & & & \\
\cline { 2 - 5 } & Reference period & Third trimester & $\mathbf{1}$ month postpartum & 3 months postpartum & 6 months postpartum \\
\hline \multirow{2}{*}{ Mother } & Third trimester & 24 & $19(79.2 \%)$ & $17(70.8 \%)$ & $18(75.0 \%)$ \\
& 1 month postpartum & & $24[5$ new cases $]$ & $18(75 \%)$ & $19(79.2 \%)$ \\
& 3 months postpartum & & $21[3$ new cases $]$ & $18(85.7 \%)$ \\
Father & Third trimester & 14 & $12(85.7 \%)$ & $12(85.7 \%)$ & $12(85.7 \%)$ \\
& 1 month postpartum & & $13[1$ new case $]$ & $12(92.3 \%)$ & $11(84.6 \%)$ \\
& 3 months postpartum & & $14[2$ new cases] & $12(85.7 \%)$ \\
\hline
\end{tabular}

Rows represent the proportions of participants defined as depression cases at a reference time point (left row heading) who continue to meet case criteria at each subsequent period. Depression cases are defined as a score above threshold on the EPDS and/or the CES-D 
Table 4

Correlations among depressive symptom severity scores in mothers and fathers

\begin{tabular}{|c|c|c|c|c|c|c|c|c|c|}
\hline \multirow[t]{2}{*}{$N=78$} & & \multicolumn{4}{|c|}{ Mother } & \multicolumn{4}{|l|}{ Father } \\
\hline & & $3^{\text {rd }}$ Tri & $1 \mathrm{~m}$ & $3 m$ & $6 \mathrm{~m}$ & $3^{\text {rd }}$ Tri & $1 \mathrm{~m}$ & $3 m$ & $6 \mathrm{~m}$ \\
\hline \multirow[t]{4}{*}{ Mother } & $3^{\text {rd }}$ Tri & & $.63^{* *}$ & $.63^{* * *}$ & $47^{* *}$ & $.27^{*}$ & .11 & .17 & .14 \\
\hline & $1 \mathrm{~m}$ & $.70^{* * *}$ & & $.61^{* * *}$ & $.43^{* * *}$ & .15 & .05 & .10 & -.04 \\
\hline & $3 \mathrm{~m}$ & $.66^{* * *}$ & $.69^{* * *}$ & & $.62^{* * *}$ & $.28^{*}$ & $.29^{*}$ & $.28^{*}$ & $.27^{*}$ \\
\hline & $6 \mathrm{~m}$ & $.55^{* * *}$ & $.65^{* * *}$ & $.61^{* * *}$ & & $.28^{*}$ & $.25^{*}$ & $.33^{*}$ & $.42^{* * *}$ \\
\hline \multirow[t]{4}{*}{ Father } & $3^{\text {rd }} \operatorname{Tri}$ & $.3^{* *}$ & $.27^{*}$ & $.24^{*}$ & $.32^{*}$ & & $.62^{* * *}$ & $.53^{* * *}$ & $.59^{* * *}$ \\
\hline & $1 \mathrm{~m}$ & $.28^{*}$ & $.28^{*}$ & $.28^{*}$ & $.22^{*}$ & $.64^{* * *}$ & & $.66^{* * *}$ & $.62^{* * *}$ \\
\hline & $3 \mathrm{~m}$ & .21 & .13 & $.25^{*}$ & $.27^{*}$ & $.57^{* * *}$ & $.70^{* * * *}$ & & $.66^{* * *}$ \\
\hline & $6 \mathrm{~m}$ & .20 & .17 & .07 & $.31^{* * *}$ & $.61^{* * *}$ & $.59^{* * * *}$ & $.75^{* * *}$ & \\
\hline
\end{tabular}

Correlations are presented for CES-D and EPDS. Cells beneath the diagonal represent the CES-D. Cells above the diagonal represent the EPDS * $p<.05$

*** $p<.01$ 